\title{
A Proposal for Classification of Neurocysticercosis
}

\author{
Arturo Carpio, Marcelo Placencia, Franklin Santillán and Alfonso Escobar
}

\begin{abstract}
The complicated pathophysiological and immunological changes in the central nervous system of patients with neurocysticercosis produce a variety of signs and symptoms, which complicate the clinical and surgical management of this disease. A complete and objective classification is needed, to improve the medical approach as a whole. We studied 336 patients, in whom we classified neurocysticerosis according to criteria of viability and location of the parasite in the CNS: active form (37.2\%) when the cysticercus is alive, transitional form $(32.8 \%)$ when it is in the degenerative phase, and inactive form $(30 \%)$ when the parasite is dead. This classification establishes the correlation between the different forms of neurocysticerosis and its clinical manifestations, and can be used for planning therapeutic strategies.
\end{abstract}

\begin{abstract}
Résumé: La neurocysticerose : ébauche de classification. Les changements physiopathologiques et immunologiques complexes du système nerveux central chez les patients atteints de neurocysticercose donnent lieu à des signes et à des symptômes variés qui compliquent le traitement clinique et chirurgical de cette maladie. Nous avons besoin d'une classification complète et objective de la neurocysticercose afin d'améliorer l'approche médicale globale. Nous avons étudié 336 patients atteints de neurocysticercose, dont nous avons classifié la maladie selon des critères de viabilité et de localisation du parasite dans le système nerveux central : la forme active (37.2\%) quand le cysticerque est vivant, la forme transitionnelle $(32.8 \%)$ quand le parasite est en phase dégénérative et la forme inactive $(30 \%)$ quand le parasite est mort. Cette classification établit la corrélation entre les différentes formes de neurocysticercose et leurs manifestations cliniques et peut être utilisée pour planifier des stratégies thérapeutiques.
\end{abstract}

Can. J. Neurol. Sci. 1994; 21:43-47

Human cysticercosis, or larval stage of the Taenia solium, is the most common parasitic illness that affects the central nervous system (CNS), especially in countries where the sanitary infrastructure is deficient. In Latin American countries, the frequency of neurocysticercosis (NC) is very high, reaching $3.6 \%$ in some regions, ${ }^{1}$ and it is becoming increasingly common in developed countries, because of immigration from endemic regions. ${ }^{2}$ We find it even in communities which do not eat pork and whose residents have not traveled to a country where $T$. solium infection is endemic. ${ }^{3}$ Since NC is a great public health problem, it is important to have a clear understanding of this disease in order to implement the necessary preventive measures.

The natural history of the cysticercus in the CNS is, to date, not completely known; however, the CT scan in the last decade, and now the MRI, ${ }^{4}$ have been very useful in the study of the biologic evolution of the cysticercosis in the CNS, especially in the brain parenchyma. Many authors have described the CT appearance of parenchymal lesions of NC related to the stage of the larva. ${ }^{5-9}$ When the larva is alive, the cyst is well circumscribed, and does not exibit contrast enhancement; on the other hand, when the larva is dead, the lesion consists of a punctate calcification. Intermediate stages between the inert cyst and calcification are varied, but all represent various stages of granuloma formation. ${ }^{5}$ These granulomatous lesions exhibit ring or nodular constrast enhancement, usually associated with cerebral edema. ${ }^{5-9}$ The MRI is useful in detecting cysts and the accompanying signs of cyst degeneration and pericystic inflammation, but it is inferior to a CT scan in the detection of parenchymal calcifications. $^{4}$

The great variability of NC clinical manifestations, characterized by remissions and relapses, has contributed to the development of a variety of $\mathrm{NC}$ classifications, which differ widely according to the criteria of each author. ${ }^{10-16}$ A classification which categorizes all the NC forms is needed, to facilitate medical and surgical management as well as research. We propose a classification which accomplishes these objectives and correlates CT findings with the pathological changes of $\mathrm{NC}$.

\footnotetext{
From the School of Medicine and Research Institute of Health Sciences of the University of Cuenca, Ecuador and G.H. Sergievsky Center, Faculty of Medicine, Columbia University in the city of New York (A.C.), the Department of Neurology "Carlos Andrade Marín" Hospital of the Ecuadorian Institute of Social Security, Quito, Ecuador (M.P.), the School of Medicine and Research Institute of Health Sciences of the University of Cuenca. Ecuador (F.S.), and the Department of Pathology of the National Institute of Neurology and Neurosurgery of México, and Department of Neurobiology Institute for Biomedical Research. University of Mexico (A.E.). RECEIVED JUNE 30, 1992. ACCEPTED IN FINAL FORM SEPTEMBER 29. 1993.

This paper was presented in part at the 19th International Epilepsy Congress (Intemational League Against Epilepsy). Rio de Janeiro, 14-19th October. 1991. Reprint requests to: Arturo Carpio, M.D. Visiting Professor, G.H. Sergievsky Center. Faculty of Medicine, Columbia University, 630W 168 Street, New York, New York 10032 U.S.A. (After July 1994: P.O. Box 719, Cuenca, Ecuador).
} 


\section{Methods}

Three hundred and thirty-six patients with NC were studied between July 1986 and June 1990. This series included all outpatients as well as inpatients treated in the "Vicente Corral Moscoso" Hospital in the city of Cuenca, Ecuador. A CT Scan with intravenous contrast injection was obtained from all patients following standardized procedures.

Cerebrospinal fluid (CSF) was obtained in all hospitalized patients (161) by lumbar puncture and was analysed according to a standardized routine, which included cell counts, sugar and total protein measurements, fungi, Koch bacili, and syphilis tests, and an enzymatic immunological (ELISA) test for cysticercosis. ${ }^{17}$ Biopsy, cisternography, angiography and myelography were carried out in some cases when the investigators judged necessary, according to the diagnostic criteria.

For this report, we considered the following clinical criteria: Seizures, according to the definition recommended by the ILAE; ${ }^{18}$ stroke, defined as an acute neurological deficit not related to epileptic seizures, originating in the distribution of a brain artery; cranial neuropathies, where a deficit of one or more cranial nerves was present, not due to a parenchymal lesion; and normal pressure hydrocephalus characterized by dementia, gait apraxia and incontinence. The other specific syndromes mentioned in this study were defined according to standardized criteria. ${ }^{19} \mathrm{NC}$ was diagnosed on the basis of CT scan images, CSF examinations and special complementary procedures, according to the criteria described below.

\section{Criteria for diagnosis and classification}

NC was classified according to viability and location of the parasite in the CNS. As to viability, the following categories were identified: 1) Active, when the parasite is alive. 2) Transitional, if it is in the degenerative phase. 3) Inactive, if there is evidence of its death. Regarding the location, the brainstemspinal and cerebral-hemispheric locations were recognized. For the purposes of this study only the cerebral-hemispheric location was classified, and each viability category was subdivided into parenchymal and extraparenchymal forms.

\section{Active forms}

Active Parenchymal The CT scan shows one or more rounded and hypodense areas of variable size without enhancement by contrast media (Figures I and 2).

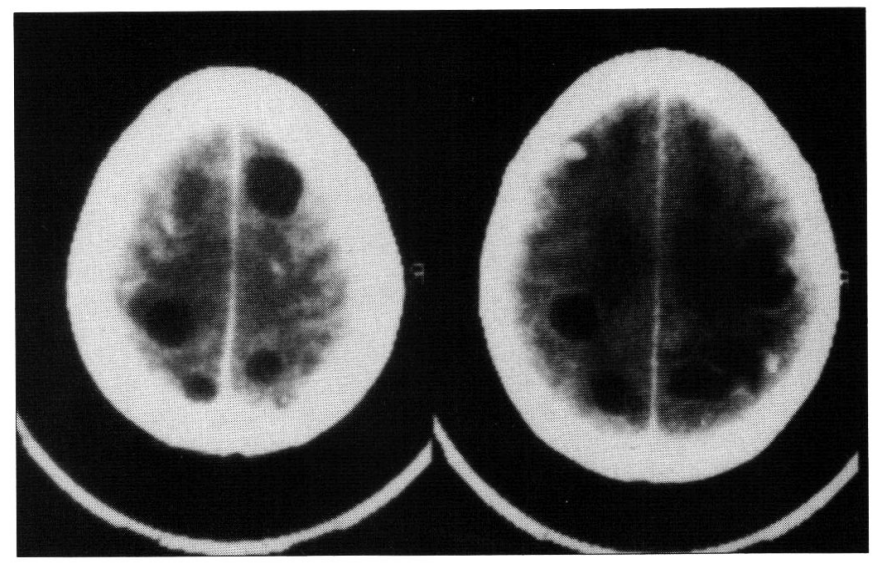

Figure 1: Post-contrast CT scans; Left, parenchymal cysts without enhancement, (active phase). Right, ring-enhancing cysts (transitional phase). Both slices show calcifications (inactive phase).

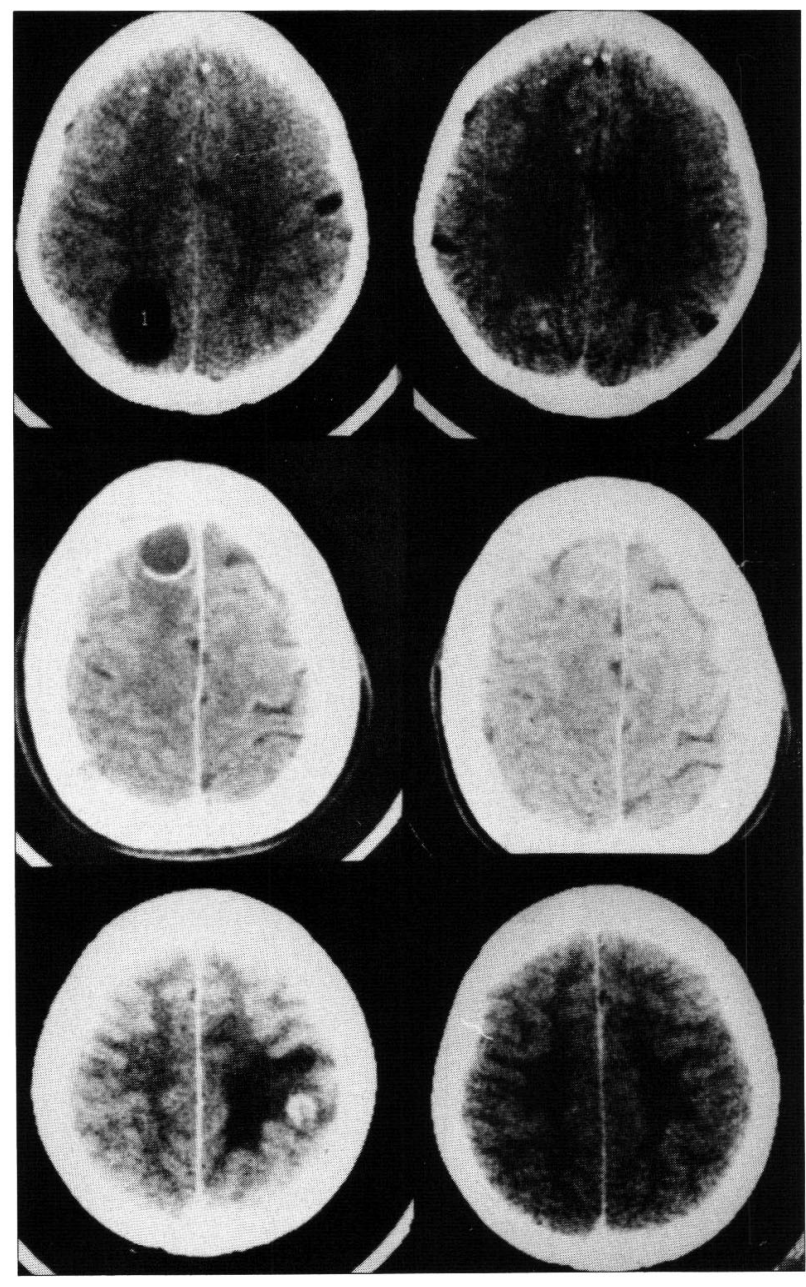

Figure 2: Post-contrast CT scans; Top left, occipital active cyst. Top right, 13 months later, the cyst was replaced by a calcification. Center left, a ring-enhanced cyst (transitional phase). Center right, three months after, it is reduced in size with homogeneous enhancement. Bottom left, a cyst with nodular contrast enhancement (transitional phase). Bottom right, two years after, the lesion has disappeared.

Active Extraparenchymal The CT scan (metrizamide cisternography) shows a hypodense image in the subarachnoid or ventricular space. The cyst deforms the surrounding structures or non-communicating hydrocephalus occurs when the cyst is located in the ventricles.

Active Parenchymal plus Extraparenchymal combination of the above forms.

\section{Transitional forms}

Transitional Parenchymal The CT scan shows either or both of the following images: 1) One or more rounded hypodense areas, with an annular enhancement surrounded by edema. (Figures 1 and 2), 2) Irregular hypodense areas, with either small nodular images, and diffuse edema, or hyperdense masses without enhancement. (Figure 2).

In the transitional parenchymal category was also included the "encephalitic" form; where the CT scan shows diffuse cerebral edema and small or collapsed ventricles. After the administration of the contrast media, multiple, small, hyperdense, nodular, or annular images were disseminated throughout the whole cerebral parenchyma. 
Transitional Meningeal Inflammatory changes in the CSF (pleocytosis above 6 cells per cubic millimeter, protein levels higher than $50 \mathrm{mg} / 100 \mathrm{ml}$, or both) with at least one of the following conditions: a) positive immunological (ELISA) test for cysticercosis in the CSF, b) subcutaneous cysticercus shown by biopsy, c) calcifications in soft parts, shown in a simple $x$-ray study. This category could be combined or not with hydrocephalus, in which CT scan shows enlarged ventricles.

Transitional Parenchymal plus Meningeal combination of the above two forms.

\section{Inactive forms}

Inactive Parenchymal One or more calcifications, shown in the CT scan by a rounded, homogeneous hyperdense area, showing no enhancement of the contrast media ${ }^{20}$ (Figures 1 and 2).

Inactive Meningeal Hydrocephalus with normal CSF in combination with the above parenchymal calcified form.

Those cases with more than one viability stage were classified according to the most active lesion detected. For example, if an individual had active, transitional, and inactive lesions, the case was considered active (Figure 1).

\section{Results}

There were $169(50.3 \%)$ females; the mean age was $35( \pm 18)$ years, with a range from 2 to 87 . The description and findings of the proposed classification are demonstrated in Table 1. The active forms were identified in $125(37.2 \%)$ patients, the transitional in $110(32.8 \%)$, and the inactive in $101(30 \%)$.

The most frequent clinical manifestations in all forms of NC (Table 2) were seizures $(71 \%)$, intracranial hypertension $(27 \%)$, cranial nerve abnormalities ( $21 \%$ ), and motor abnormalities $(16 \%)$, followed by dementia $(8 \%)$, stroke $(7 \%)$, and cerebellar syndrome $(7 \%)$. Other syndromes, such as, confusional, chiasmatic, extrapyramidal, periaqueductal, and normal pressure hydrocephalus, appeared in lower percentages.

The frequency of clinical manifestations corresponding to each NC form is shown in Table 2. Seizures were more common in all parenchymal forms $(75-88 \%)$, than in the extraparenchymal (0\%-50\%). Intracranial hypertension was more frequent in the extraparenchymal forms $(86 \%-100 \%)$ than in the parenchymal (0-18\%). Cranial nerve abnormalities were present in $78 \%$ of the transitional parenchymal plus meningeal forms, in $60 \%$ of the meningeal forms, and in only $8 \%$ of the inactive parenchymal forms. Differences between the clinical manifestations of parenchymal and extraparenchymal forms were significantly different in all cases (Chi square test: $p$ values $<0.005$ ).

\section{Discussion}

Before the advent of the CT scan, several authors published different classifications of NC based on varied clinical and anatomical criteria. ${ }^{10-13} \mathrm{NC}$ is characterized by clinical polymorphism; in almost every patient the disease takes its own particular course, depending on personal immune reponse, the severity of infection, and the location and number of parasites. ${ }^{21}$ This has caused difficulties in developing a uniform criterion for $\mathrm{NC}$ classification among different authors.
Table 1. Classification of Neurocysticercosis.

\begin{tabular}{|c|c|c|}
\hline $\begin{array}{c}\text { VIABILITY } \\
\text { Location }\end{array}$ & $\begin{array}{l}\text { Number of } \\
\text { patients }\end{array}$ & Percentage \\
\hline \multicolumn{3}{|l|}{ ACTIVE: 125 (37.2) } \\
\hline Parenchymal & 90 & $26.7 \%$ \\
\hline Extraparenchymal* & 7 & $2.1 \%$ \\
\hline Parench.+ Extraparench. & 28 & $8.3 \%$ \\
\hline Total Active & 125 & $37.2 \%$ \\
\hline \multicolumn{3}{|l|}{ TRANSITIONAL I $10(32.8)$} \\
\hline Parenchymal & 82 & $24.4 \%$ \\
\hline Meningeal & 10 & $2.9 \%$ \\
\hline Parench.+ Mening. & 18 & $5.3 \%$ \\
\hline Total Transitional & 110 & $32.8 \%$ \\
\hline \multicolumn{3}{|l|}{ INACTIVE 101 (30) } \\
\hline Parenchymal & 87 & $25.9 \%$ \\
\hline Meningeal & 14 & $4.1 \%$ \\
\hline Total Inactive & 101 & $30.0 \%$ \\
\hline TOTAL FOR ALL PATIENTS & 336 & $100.0 \%$ \\
\hline
\end{tabular}

*Includes subarachnoid-meningeal and intraventricular locations.

Table 2. Clinical Manifestations in 336 Patients with Neurocysticercosis.

\begin{tabular}{|c|c|c|c|c|c|}
\hline $\begin{array}{l}\text { VIABILITY } \\
\text { Location }\end{array}$ & $\begin{array}{l}\text { No. } \\
\text { Patients }\end{array}$ & $\begin{array}{c}\text { Seizures } \\
\mathbf{n}(\%)\end{array}$ & $\begin{array}{c}\mathbf{I . H} \\
\mathbf{n}(\%)\end{array}$ & $\begin{array}{l}\text { M.A. } \\
\text { n(\%) }\end{array}$ & $\begin{array}{l}\text { C.N.A** } \\
\text { n(\%) }\end{array}$ \\
\hline \multicolumn{6}{|l|}{ ACTIVE } \\
\hline Parenchymal & 90 & $74(82)$ & $9(10)$ & $22(24)$ & $14(15)$ \\
\hline Extraparenchymal & 7 & 0 & $6(86)$ & $1(14)$ & $2(10)$ \\
\hline Parench.+ Extraparen. & 28 & $12(43)$ & $24(86)$ & $8(28)$ & $10(38)$ \\
\hline \multicolumn{6}{|l|}{ TRANSITIONAL } \\
\hline Parenchymal & 82 & $72(88)$ & $15(18)$ & $12(14)$ & $12(14)$ \\
\hline Meningeal & 10 & $2(20)$ & $10(100)$ & $1(10)$ & $6(60)$ \\
\hline Parench.+ Mening. & 18 & $6(33)$ & $16(89)$ & $6(33)$ & $14(78)$ \\
\hline \multicolumn{6}{|l|}{ INACTIVE } \\
\hline Parenchymal & 87 & $66(75)$ & 0 & 3 (3) & $7(8)$ \\
\hline Meningeal & 14 & $7(50)$ & $12(86)$ & $2(14)$ & $6(4)$ \\
\hline TOTAL & 336 & $239(71)$ & $92(27)$ & $55(16)$ & $71(21)$ \\
\hline
\end{tabular}

* I.H: Intracranial hypertension. M.A: Motor abnormalities.

C.N.A: Cranial nerve abnormalities.

- Number and percentage of patients in each of the NC categories.

A criterion based on the prognosis of the illness as malignant or benign seems useful, ${ }^{15}$ but it limits itself to this particular factor of the prognosis. Other investigators used such ambiguous terms as "acute encephalic",22 "encephalitic cysticercosis"23,24 "acute edematosis", and "tumoral edematosis", ${ }^{8}$ which are related terms that refer to specific clinical and radiological syndromes.

Sotelo et al. ${ }^{14}$ propose an interesting classification criterion using active and inactive forms based on the viability, which 
means that the parasite could be alive or dead in the CNS of the host. However, their definition of active and inactive is unclear. Among the so-called "active forms", they include cysts in a degenerative process, where the parasite is dead and therefore belongs to another specific evolutionary stage, with different clinical and therapeutic repercussions. Likewise, they included cysticercotic arachnoiditis among the active forms, but it is not clear how they demonstrated the viability of the parasite in this NC form. More than $50 \%$ of their patients belonged to the "combined" forms, but they did not specify the type of combination, and their study also lacks clinical correlation. Bittencourt et al. ${ }^{16}$ propose a modification of this classification, by simplifying the active forms to intraparenchymal and extraparenchymal, but they did not categorize a high percentage of patients that have active and inactive forms combined.

The viability criterion is very important, as it allows us to analyze the natural history of the parasite, and, according to the parasite's evolutionary stage, the production of physiopathological changes in the host's CNS. Identification of the phase of implantation of the parasite in the CNS is, so far, imperfect; but once the parasite is established in the parenchyma, it evolves through vesicular, colloidal, granular-nodular and calcified phases. ${ }^{25}$ So far there is no experimental evidence that reflects this sequence; nevertheless, CT scanning or MRI can identify these phases.

In the vesicular phase the larva lives in a transparent liquid, surrounded by a thin, translucent, white membrane, and it can remain viable for anywhere from a few months to several years. ${ }^{25}$ When the larva is viable, the CT scan shows circumscribed hypodense areas, of variable size and number, without enhancement of contrast media. ${ }^{5-9}$ This phase corresponds to the "active parenchymal" form in our classification (Figures 1 and 2).

During the transitional phase two pathological changes take place: $i)$ in the colloidal phase, the parasite begins to show degenerative changes, the vesicular liquid takes on a gelatinouscolloidal aspect, and the wall begins to thicken. ${ }^{25}$ The CT scan in this phase shows an annular captation of the contrast media, surrounded by an irregular perilesional edema (Figures 1 and 2). ii) in the nodular-granular phase, the vesicle tends to shrink, and its content becomes semisolid, being progressively replaced by granulomatous tissue. ${ }^{25}$ These findings could correspond to the simple CT scan that shows a diffuse hypodense area with irregular borders; after the administration of the contrast media, we observe a small hyperdense, rounded, nodular image surrounded by edema (Figure 2 ). In these two consecutive phases the parasite appears to be dying; thus, it cannot be considered either as active, nor as "inactive", due to the inflammatory response of the cerebral tissue. It is an intermediate form, that some authors call the acute phase. ${ }^{26.27} \mathrm{We}$ feel that this name is somewhat ambiguous, due to the unknown duration of this sequence. We propose a new category, therefore, which we call "transitional", inasmuch as the cysticercus is in a degenerative process. ${ }^{28,29}$

The cysts in the transitional phase may be single or multiple. In the latter case (Figure 1), if they are combined with other cysts in the vesicular phase and disseminated calcifications in the cerebral parenchyma, the most likely diagnosis is NC. However, when there is only one cyst in the transitional phase, the differential diagnosis must take into account other pathologies, such as tuberculoma, abscess, and metastasis. ${ }^{5,9,29.30}$ During these stages there is an inflammatory reaction of the brain tissue adjacent to the cyst and marked cerebral edema. Although these pathological changes are responsible for symptomatology, usually consisting of seizures or headaches, this reaction may not cause any symptoms at all.

One of the NC forms that has different clinical and radiological characteristics from those described above is the so-called "cysticercosis encephalitis" that occurs in children and young women. ${ }^{6,23,24}$ The CT scan image, as described above, is very definitive. These images may appear during the implantation phase or may be associated with the degenerative stage, that is, during a transitional form. The underlying pathology in the encephalitic phase appears as an intense inflammatory reaction composed of lymphocytic, plasmocytic and eosinophilic cell exudate. $^{25}$

Finally, the dead organism is reabsorbed, or a mineralization process occurs until it calcifies and lodges permanently in the CNS. ${ }^{25}$ This calcification is a sequel to the final phase of parasite evolution. It is the "inactive" form of the $\mathrm{NC}^{14}$ and corresponds to the "inactive parenchymal" form in our classification (Figures 1 and 2).

The parasite can also be located in the subarachnoid space or inside the ventricular system, where its evolutive process is little known. Surgical data establish that the parasite in this location is in the vesicle stage; ${ }^{31.32}$ therefore, it corresponds to the active extraparenchymal form of our classification. On rare occasions and for causes still unknown, the cysticercus located in the subarachnoid space can evolve into the racemose form of $\mathrm{NC}$; in our series there were 7 such cases. The racemose form ("Traubenhydatiden") develops when the parasite vesicles are located in the arachnoidal cisterns. The cysts undergo hydropic degeneration resulting in large bullous vesicles. ${ }^{25}$

When the parasite is located in the subarachnoid space, it can also cause a meningeal inflammatory process, pleocytosis, and increased CSF protein. ${ }^{\mid 4.16 .33 .34}$ The parasite is trapped inside the gummatous thickening of the leptomeninges. Proper identification of the parasite is done through histological examination of stained sections. ${ }^{25}$ Arachnoiditis produces obstruction of the CSF circulation and hydrocephalus. Although we could interpret this disorder as an immunological reaction against the cysticercus inside the subarachnoidal space, ${ }^{14}$ this does not necessarily indicate the viability of the parasite. Therefore, this process cannot be identified as an active or inactive form. We prefer to call it a "transitional meningeal" form.

As a sequel to the above inflammatory process, fibrosis of the leptomeninges may cause chronic hydrocephalus. ${ }^{25.34}$ Viewed with the naked eye, it is difficult to differentiate one specimen with basal meningitis from other chronic infectious pathologies, e.g., tuberculous meningitis. Moreover, a normal CSF study neither eliminates nor confirms the cysticercosis diagnosis or the parasite viability. We believe that the only way to identify this form of $\mathrm{NC}$ is by detection of the calcifications in the cerebral parenchyma, which indirectly establishes the "etiology" of this finding. This is the "inactive meningeal" form in our classification.

On the basis of our results, it is possible to relate clinical manifestations to each category of the proposed classification. For example, seizures were the main symptom in the majority of patients with active $(82 \%)$ and transitional parenchymal forms $(88 \%)$ to which the inflammatory reaction of the adjacent brain tissue may also contribute as a trigger factor. On the other hand, the cranial nerve abnormalities and the intracranial hypertension syndromes were more frequent in the meningeal forms, due to the arachnoiditis process. 
Some authors ${ }^{21.35}$ recommend the use of anticysticercal drugs in almost all $\mathrm{NC}$ forms except the calicified one. We feel that in the transitional phase, neither anticysticercal drugs nor surgery ${ }^{3.29}$ are necessary because the parasite is dying and the infection is resolving spontaneously. It is usually possible to control the symptoms by means of symptomatic therapy. ${ }^{27.36}$ Some physicians would administer anticysticercal drugs for the active forms of NC in order to accelerate the death of the parasite..$^{37}$ However, since parasite death occurs naturally, some authors prefer not to actively intervene with therapy. ${ }^{29.38 .39}$ These arguments may become academic in view of the results of a recent study ${ }^{40}$ which supports the position of treating both active and transitional phases of cysticercosis since seizure activity appears to be improved by antihelmintic therapy, even when the parasite is dying. Further studies are needed to confirm this work.

Our proposed classification allows the design of research projects to evaluate the effectiveness of anticysticercal drugs and improve the study of the clinical manifestations of all NC forms.

\section{ACKNOWLEDGEMENTS}

Supported by a grant from the "Consejo Nacional de Universidades y Escuelas Politécnicas del Ecuador" (CONUEP).

The authors thank Dr. Ion Youman for translation assistance.

\section{REFERENCES}

I. Costero I. Tratado de anatomía patológica. México: Editorial Atlante; 1946: 1485-1495.

2. Couldwell WT, Chi-Shing Z, Apuzzo MLJ. Definition of contemporary surgical management in cisternal and parenchymatous cysticercosis cerebri. Neurosurgery 1991; 28: 231-237.

3. Schantz PM, Moore AC, Muñoz JL, et al. Neurocysticercosis in an orthodox Jewish community in New York city. N Engl J Med 1992; 327: 692-695.

4. Lotz J, Hewlett R, Alheit B, Bowen R. Neurocysticercosis: correlative pathomorphology and MR imaging. Neuroradiology 1988; 30: $35-41$.

5. Enzmann DR. Imaging of Infections and Inflammations of the Central Nervous System. New York: Raven Press; 1984: 102-127.

6. Rodríguez-Carbajal J, Palacios G, Zee CH. Neuroradiology of the cysticercosis of the central nervous system. In: Palacios E, Rodríguez-Carbajal J, Taveras J, eds. Cysticercosis of the Central Nervous System. Springfield: Charles C Thomas 1983: 101-143.

7. Mervis B, Lotz JW. Computed tomography (CT) in parenchymatous cerebral cysticercosis. Clin Radiol 1980; 31: 521-528.

8. Byrd SHE, Locke GE, Biggers S, et al. The computed tomography appearance of cerebral cysticercosis in adults and children. Radiology 1982; 144: 819-823.

9. Handler LC, Mervis B. Cerebral cysticercosis with reference to the natural history of parenchymal lesions. Am J Neuroradiol 1983; 4: 709 .

10. Dixon HBF, Lipscomb FM. Cysticercosis: an analysis and followup of 450 cases. Med Res Council Spec Rep, London, Her Majesty's Stationary Office 1961; 299: 1-58.

11. Stepien L. Cerebral cysticercosis in Poland. Clinical symptoms and operative results in 132 cases. J Neurosurg 1962; 19: 505-513.

12. Alarcón GT, Olivares L. Cisticercosis cerebral: manifestaciones clínicas en un medio de alta prevalencia. Rev Invest Clin 1975; 27: 209-215.

13. Zenteno Alanís GH. Aspectos fisiopatológicos en el tratamiento quirúrgico de la cisticercosis humana. Cirugía y Cirujanos 1983; 512: 45-160.

14. Sotelo J, Guerrero V, Rubio F. Neurocysticercosis: a new classification based on active and inactive forms. A study of 753 cases. Arch Intern Med 1985; 145: 442-445.
15. Estañol B, Corona T, Abad P. A prognostic classification of cerebral cysticercosis: therapeutic implications. J Neurol Neurosurg Psychiatry 1986; 49: 1131-1134.

16. Bittencourt PRM, Costa AJ, Oliveira TV, et al. Clinical, radiological and cerebrospinal fluid presentation of neurocysticercosis. A prospective study. Arq Neuro-Psiquiat (Sao Paulo) 1990; 48: 286-295.

17. Palacios $\mathrm{R}$, Alvarado $\mathrm{M}$, Carpio A, et al.Valoración de las técnicas inmunológicas en el diagnóstico de la cisticercosis cerebral. Rev Inst Invest Cienc Salud, Univ. de Cuenca 1988; 3: 1-19.

18. Commission on Classification and Terminology of the International League Against Epilepsy. Proposal for revised clinical and electroencephalographic classification of epileptic seizures. Epilepsia 1981; 2: 489-501.

19. Haymaker W. Bing's Local Diagnosis in Neurological Diseases. Saint Louis: Mosby Company; 1969.

20. Rodriguez-Carbajal J, Placencia M, Carpio A. Calcificaciones intracraneales anormales: 135 casos estudiados por T.A.C. Neurol Neurocir Psiquiat 1983; 24: 49-60.

21. Del Brutto O, Sotelo J. Neurocysticercosis: an update. Rev Infect Dis 1988; 10: 1075-1087.

22. Rodríguez Carbajal J, Salgado P, Gutierrez-Avarado R, et al. The acute encephalitic phase of neurocysticercosis: computed and tomographic manifestations. Am J Neuroradiol 1983; 4: 51-55.

23. López-Hernández A, Garaizar C. Childhood cerebral cysticercosis: clinical features and computed tomographic findings in 89 Mexican children. Can J Neurol Sci 1982; 9: 401-407.

24. Rangel R, Torres B, Del Brutto O, et al. Cysticercotic encephalitis: a severe form in young females. Am J Trop Med Hyg 1987; 36: 387-392.

25. Escobar A. The pathology of neurocysticercosis. In: Palacios E, Rodríguez-Carbajal J, Taveras J, eds. Cysticercosis of the Central Nervous System. Springfield: Charles C Thomas Publisher; 1983: 27-54.

26. Kramer LD, Locke GE, Bird SE, et al. Cerebral cysticercosis: documentation of natural history with CT. Radiology 1989; 171: 459462.

27. Mitchel WG, Crawford TO. Diagnóstico y tratamiento de la cisticercosis cerebral intraparenquimatosa en los niños. Pediatrics (ed esp) 1988; 26: 63-69.

28. Carpio A, Placencia M, Escobar A, et al. Proposal for a new classification of neurocysticercosis. Presented at the 19 th International Epilepsy Congress, Rio de Janeiro, Brasil. Oct 14-19, 1991.

29. Carpio A, Placencia M. Definition of contemporary surgical management in cisternal and parenchymatous cysticercosis cerebri. Neurosurgery 1992; 30: 968-969.

30. Bhatia S, Tandom PN. Solitary "microlesions" in CT: a clinical study and follow-up. Neurol India. 1988; 36: 139-150.

31. Madrazo I, García-Rentería J, Sandoval M, et al. Intraventricular cysticercosis. Neurosurgery $1983 ; 12: 148-152$.

32. Apuzzo MLJ, Dobkin WR, Chi-Shing Zee, et al. Surgical considerations in treatment of intraventricular cysticercosis: an analysis of 45 cases. J Neurosurg 1984; 60: 400-407.

33. McCormick GF, Zee CH, Heiden J. Cysticercosis cerebri. Review of 127 cases. Arch Neurol 1982; 39: 534-544.

34. Carpio A, Ochoa M, Parra P, et al. Meningitis crónica: revisión de 47 casos. Rev Inst Invest Cienc Salud, Univ. de Cuenca 1987; 2 : $1-15$.

35. Robles C, Sedano AM, Vargas-Tentori N, et al. Long-term results in praziquantel therapy in neurocysticercosis. J Neurosurg 1987; 66: 359-363.

36. Miller B, Grinnell V, Goldberg MA, et al. Spontaneous radiographic disappearance of cerebral cysticercosis: three cases. Neurology 1983; 33: 1377-1379.

37. Carpio A, Santillán F, León $P$, et al. New treatment of brain cysticercosis with albendazol. Ann Neurol 1988; 24: 144.

38. Moodley M, Moosa A. Treatment of neurocysticercosis: is praziquantel the new hope? Lancet 1989; 1:262-263.

39. Kramer LD. Antihelminthic therapy for neurocysticercosis. Arch Neurol 1990; 47: 1059-1060.

40. Vazquez $\mathrm{V}$, Sotelo $J$. The course of seizures after treatment for cerebral cysticercosis. N Engl J Med 1992; 327: 696-701. 